\title{
Twin Reverse Arterial Perfusion (TRAP): Case Report
}

\author{
Natalia Adamou, Ibrahim Yakasai* \\ Department of Obstetrics and Gynaecology, Bayero University Kano, Kano, Nigeria \\ Email: ${ }^{*}$ ibrahimyakasai57@hotmail.com
}

Received 23 September 2014; revised 20 October 2014; accepted 15 November 2014

Academic Editor: Yasam Kemal Akpak, Ankara Mevki Military Hospital, Turkey

Copyright (C) 2014 by authors and Scientific Research Publishing Inc.

This work is licensed under the Creative Commons Attribution International License (CC BY).

http://creativecommons.org/licenses/by/4.0/

(c) (i) Open Access

\section{Abstract}

The twin reversed arterial perfusion (TRAP) sequence is an anomaly unique to monochorionic multiple pregnancies. It is a rare complication. We present a case of acardius anephus, which was mistaken for a live anomalous singleton fetus. A 21-year-old unbooked Primigravida was seen in labour ward with a ten hours history of labour pains. Urgent transabdominal ultrasound revealed a singleton live fetus at 30 weeks gestation with gross cystic mass lesion at the level of the abdomen and polyhydramnious. Caesarean section confirms a twin gestation with monoamniotic monochorionic single placenta. The umbilical cord of the acardiac twin was short-First twin was a live female baby, weighing $1000 \mathrm{~g}$. TRAP is a rare event an early referral to feto maternal unit will improve perinatal outcome.

\section{Keywords}

Acardiac Twin, Twin Reversed Arterial Perfusion, Monochorionic Multiple Pregnancy

\section{Introduction}

The twin reversed arterial perfusion (TRAP) sequence or acardiac twinning, or chorioangiopagus parasiticus is an anomaly unique to monochorionic multiple pregnancies [1]. It is a rare complication that affects 1 in 100 monozygotic twin pregnancies and 1 in 35,000 overall, with no recognized familial recurrence [1].

The acardiac twin is a true parasite. Theories explaining pathogenesis of the anomaly attribute it to either dysmorphogenesis or presence of arterio-arterial anastomosis, with the latter being the most popular. Dysmor-

*Corresponding author. 
phogenesis or cardiac dysmorphogenesis theory holds that a lethal heart malformation in early organogenesis seems a likely underlying pathology (so called "cardiac regression sequence") [2]. Arterio-arterial anastomosis - this theory holds that there is a reversed blood flow from umbilical artery of the pump twin into the umbilical artery of the perfused twin thereby bypassing the placenta, therefore poorly oxygenated blood contributes to deficient development of the head, upper limbs, torso and heart while better oxygenated blood flowing via umbilical artery through the common iliac artery and aorta allow better development of the lower part of the body [1]-[3].

Four morphological types of acardiac twins were described. Acardius anephus (most common type) present with absence of the head, upper limbs, and torso but with preservation of the lower limbs, genitalia and viscera. Acardius anceps (most developed type) lacks even rudimentary heart and present with rudimentary cranial structures. Acardius amorphous (least differentiated type) - comprises of an amorphous mass of bones, muscles, fat and connective tissues. Acardius acormus (rarest type)—present with the head as the only developed structure while all other structures are essentially absent [3] [4].

The diagnosis is made on ultrasound scan by demonstration of the poor definition of the head, trunk and upper extremities, or abnormal cystic areas in the upper part of the body of the affected twin, and the absence of identifiable cardiac pulsation [5]. A Doppler study is used to demonstrate reverse flow through the umbilical arteries to the affected fetus. The difference between the pump twin and the acardiac twin resistance index (RI) of more than 0.2 is associated with a good prognosis [3]. In $75 \%$ of cases the umbilical cord of the recipient twin contains a single umbilical artery [3] [5]. The 3D sonographic evaluation helps in assessment of the sequence, its extent and severity. The (3D) sonographic body volume estimation is better parameter for reflecting the size of a twin and can assist the management, as sonographic 2D fetal weight estimation is not clinically applicable due to amorphous structures of the acardic twin [6]. In doubtful cases magnetic resonance imaging (MRI) can be offered [7].

The major complication that affects the pump twin is high-output congestive cardiac failure which is secondary to the strain of perfusing the acardiac twin. The high cardiac output increases perfusion of the fetal kidneys, leading to overproduction of fetal urine and polyhydramnion [3]. The prognosis depends on the weight of the acardiac and the pump twin. If the weight of the acardiac twin is higher than pump twin the prognosis is worse. It was documented that when an acardiac/pump ratio is above $70 \%$ at birth, the incidence of preterm delivery is $90 \%$, polyhydramnion is $40 \%$ and congestive cardiac failure is $30 \%$ [3]. Perinatal mortality rates up to $50 \%-75 \%$ [8] [9] have been reported.

We present a case of acardiac twin which was mistaken for a live anomalous singleton fetus. To best of our knowledge such condition was not reported in our center or similar tertiary centers in Nigeria.

\section{Case Report}

An informed consent was obtained from the patient and the hospital ethical committee gave approval for this case report,

A 21-year-old unbooked Hausa Nigerian primigravida was seen in labour ward on 1/12/2011 with a ten hours history of labour pains. It was not associated with drainage of liquor or bleeding per vagina. She was unsure of her last menstrual period, but had a transabdominal ultrasound scan at 18 weeks, which she was told revealed a single fetus with no anomaly and gave an expected date of delivery on 6/02/2012. The estimated gestational age was 30 weeks and 3 days. Her family history was not contributory for twin pregnancy. She had no history suggestive of infections or illicit drug ingestion, during first trimester.

Her clinical examination revealed a young woman in intermittent painful distress, not pale, anicteric and afebrile. She was well hydrated and had no pedal oedema. Her vital signs were stable. The abdomen was tense with a symphysio-fundal height of 42 centimeters. It was difficult to appreciate uterine contractions and fetal parts but heart sound was present. Vaginal examination revealed a cervical dilatation of 5 centimeters with intact membranes. The presenting part was difficult to appreciate. Urgent transabdominal ultrasound scan was done in labour ward, which revealed a singleton live fetus lying transversely at 30 weeks with gross cystic mass at the level of the abdomen and polyhydramnion. An assessment of preterm labour with anomalous fetus was made.

She subsequently had an emergency caesarean section. Intraoperative findings were: polyhydramnious of two liters, twin gestation, and single monoamniotic monochorionic placenta. The umbilical cord of the acardiac twin was very short -20 centimeters with a single artery. First twin was a live female baby, weighing $1000 \mathrm{~g}$ in left 
acramiodorsal position, delivered by breech delivery, with APGAR scores of 1 and 4 in the first and fifth minutes respectively. The second twin had amorphous upper torso, head and limbs with relatively well formed lower limbs, female external genetalia and plethoric skin. It weighed $3200 \mathrm{~g}$.

The first twin was resuscitated and transferred to the special care baby unit, where it was found to be in cardiac failure with severe respiratory distress. The baby however died 17 hours later despite intensive care.

The patient declined autopsy and radiography despite adequate counseling.

She was discharged on fifth postoperative day in satisfactory condition (Figure 1 and Figure 2).

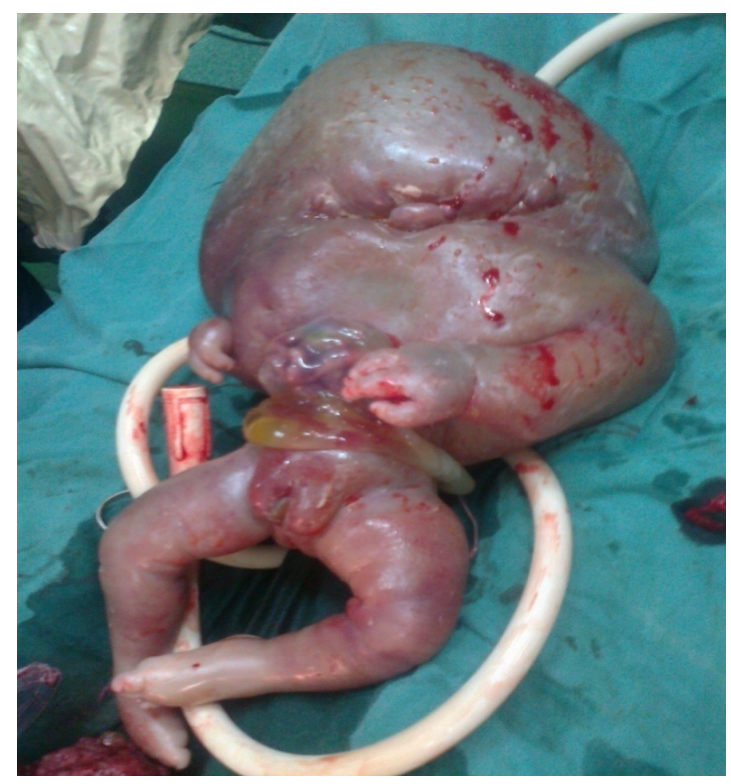

Figure 1. Amorphous twin.

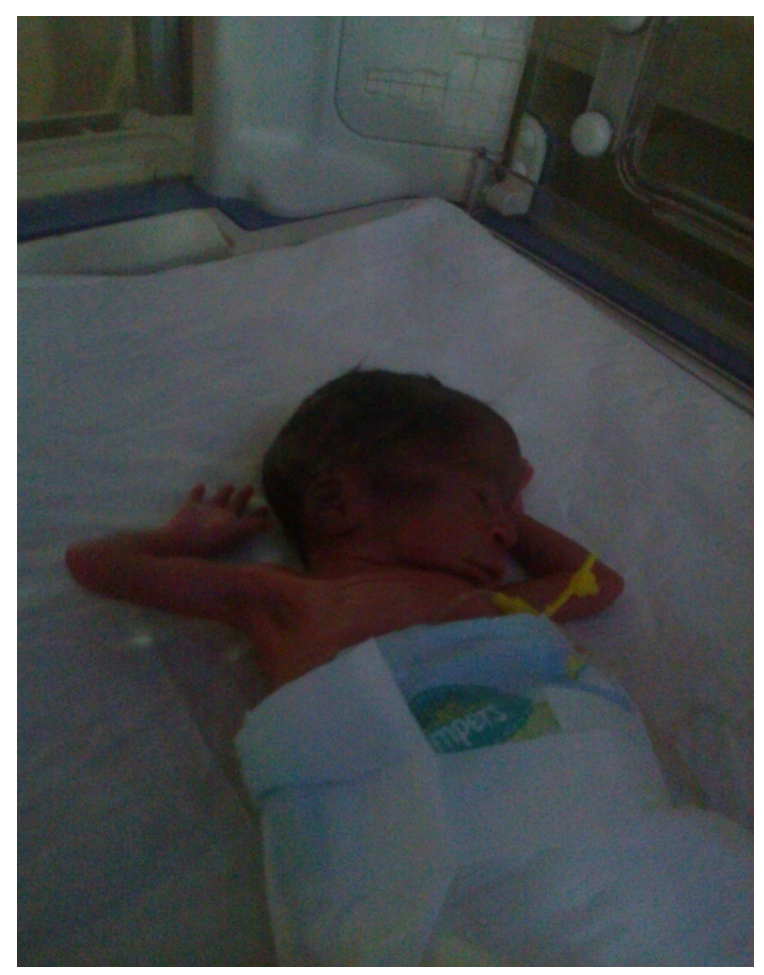

Figure 2. Live preterm twin. 


\section{Discussion}

The twin reversed arterial perfusion is a rare condition with a non-viable acardiac twin and a lot of risks to the pump twin (prematurity, cardiac failure, hydrops and intrauterine demise). It was first described in 1942 [9]. This condition cannot be prevented and is unique to monozygotic monochorionic twin gestations, and if untreated is associated with a high $(50 \%-75 \%)$ perinatal mortality of the pump twin, especially when acardiac/twin ratio is greater than $70 \%$ of the size of the pump twin by estimated weight [2] [4]. It is more common in nulliparous women [4]. The pump twin is structurally normal, may develop polyhydramnious and cardiac failure. The acardiac twin is usually grossly abnormal with oligohydramnious and two-vessel umbilical cord. The sequence can manifest as early as 11 weeks of gestational age [10]. The diagnosis of TRAP is said to be challenging as it was in this case. First trimester scan is necessary to determine chorionicity and is preferably done before 14 weeks gestational age (100\% sensitivity, 99\% specificity) [1] while still the amniotic membrane is separated from the chorion. However, this patient, had the first scan at 18 weeks elsewhere, and was told it was normal (she lost the printed report before presenting to us), in addition she presented only to our unit at 30 weeks of gestational age in labour. After the first scan, she should have had a follow up scan with Doppler scan which will demonstrate umbilical artery blood flow and predict presence of a large anastomosis, and the in utero condition of the twins.

Management options are majorly conservative, palliative and invasive treatment. The choice is dictated by gestational age, size of the acardiac twin, availability of a trained paediatric surgeon, specialized equipment which is mostly deficient in developing country like ours. Conservative management includes a close antenatal surveillance and timed delivery if there is compromise in the pump twin. It is suitable for a less severe case when pump twin dominates [10] [11]. Palliative treatment involves prolongation of pregnancy by serial amnioreduction. The perinatal mortality from above treatments was reported as $10 \%-55 \%$ [1] [10]. Invasive treatment interrupts the blood flow to the acardiac twin using hysterotomy and selective delivery of the acardiac twin; embolization of the acardiac circulation by thromboembolic substances; fetoscopic cord ligation and ultrasound guided coagulation of the umbilical cord using laser or radiofrequency ablation. Hysterotomy and selective delivery of the acardiac twin is no longer performed, as this is associated with high maternal and fetal complications, and less invasive techniques are available [12] [13]. Percutaneous ultrasound guided intra-fetal alcohol injection is simpler and compared to endoscopic procedures is inexpensive and can be used in low income countries, where we practice [12] [13]. Ultrasound guided coagulation of the umbilical cord using laser or radiofrequency ablation can be performed as early as $16-24$ weeks and is associated with survival rate of $80 \%-88 \%$ and delivery at a median gestation of 38 weeks [14]-[16].

Complications of these techniques include hemorrhage, rupture of membranes, preterm births and fetal demise, as a result of insertion of devices into the uterus [15] [17] [18]. High-intensity focused ultrasound (HIFU) treatment is a new non-invasive modality for the treatment of reversed arterial perfusion. It is used to denaturate the fetal blood vessels using external ultrasound waves without direct fetal contact [16]. However, such specialized equipment is only available in a few centers around the world [13].

While an earlier diagnosis in our center might not have resulted in the cutting-age procedures of minimally invasive techniques such as ultrasound guided cord coagulation by laser or radio-frequency ablation, which can be performed as early as 16 weeks, due to unavailability, the patient could have had a chance of conservative management, which including antenatal surveillance, serial amnioreduction and timed delivery. In this case Intraoperatively, we found polyhydramnion of 2 liters, live first twin weighing $1000 \mathrm{~g}$ with Apgar scores of 1 and 4, amorphous second twin weighing $3200 \mathrm{~g}$ (acardiac/pump ratio was 68\%) and single monoamniotic monochorionic placenta. In this case, the pump twin died 17 hours after delivery due to cardiac decompensation and prematurity, we believe serial amnio-reduction and antenatal fetal surveillance would have given a better outcome in this patient

\section{Conclusion}

It is important to do ultrasonographic evaluation early in pregnancy by a trained sonologist to detect TRAP. Referral to a feto-maternal unit in a specialized center would then be the rule. Unfortunately in this case outcome was unfavorable as the case was missed from the beginning. If this condition was identified earlier in pregnancy, probably pump twin would have had better outcome. 


\section{References}

[1] Liesbeth, L. and Deprest, J. (2006) Fetal Problems in Multiple Pregnancy. In: James, D.K., Steer, P.J., Weiner, C.P. and Gonic, B., Eds., High Risk Pregnancy Management Options, 3rd Edition, Elsevier Inc., Philadelphia, pp. 524-561.

[2] Prasad, R.H., Prasad, T.R. and Kumar, K.D. (2012) TRAP Sequence-An Interesting Entity in Twins. Journal of Clinical Imaging Science, 2, 56. http://dx.doi.org/10.4103/2156-7514.100997

[3] Chandramouly, M. and Namitha (2009) Case Series: TRAP Sequence. Indian Journal of Radiology and Imaging, 19, 81-83. http://dx.doi.org/10.4103/0971-3026.45352

[4] Athita, C. and Densak, P. (2007) TRAP Sequence in an Acardiac Twin. Journal of the Medical Association of Thailand, 90, 819-822.

[5] Tan, T.Y. and Supulveda, W. (2003) Acardiac Twin: Systematic Review of Minimally Invasive Treatment Modalities. Ultrasound in Obstetrics \& Gynecology, 22, 409-419. http://dx.doi.org/10.1002/uog.224

[6] Bornstein, E., Monteagudo, A., Schwartz, N. and Ilan, E.T. (2008) Detection of Twin Reversed Arterial Perfusion Sequence at the Time of First-Trimester Screening. Journal of Ultrasound in Medicine, 27, 1105-1109.

[7] Zeev, B., Abdallah, W., Onit, S.G. and Brook, O.R. (2008) Triplet Gestation-Prevention, Risk and Management Dilemmas. The Open Women's Journal, 2, 11-21.

[8] Bavarian, Sadidi, S. and Hassanzadeh, P. (2007) Acardiac Parabiotic Twin: A Case Report. A Case of Acardiac Parabiotic Twin 252 Iran. J. Radiol., 4.

[9] Pandey, K., Arya, S. and Kaitiyar, G. (2010) A Rare Case of Acardiac Acephalus Twin Pregnancy. Journal of Obstetrics and Gynaecology of India, 60, 75-76. http://dx.doi.org/10.1007/s13224-010-0003-6

[10] Weisz, B., Peltz, R., Chayen, B., Oren, M., Zalel, Y., Achiron, R., et al. (2004) Tailored Management of Twin Arterial Perfusion (TRAP) Sequence. Ultrasound in Obstetrics \& Gynecology, 23, 451-455. http://dx.doi.org/10.1002/uog.1040

[11] Amy, E., Michael, W., Robert, H., Marc, J. and Robert, M. (2003) The Management of Acardiac Twins: A Conservative Approach. American Journal of Obstetrics and Gynecology, 189, 1310-1313. http://dx.doi.org/10.1067/S0002-9378(03)00597-0

[12] Richard, P. (2004) Percutaneous Ultrasonographically Guided Ablation of an Active Twin. American Journal of Obstetrics and Gynecology, 190, 572-574.

[13] Sepulveda, W., Sfeir, D., Reyes, M. and Martinez, J. (2000) Severe Polyhydramnios in Twin Reversed Arterial Perfusion Sequence: Successful Management with Intrafetal Alcohol Ablation of Acardiac Twin and Amniodrainage. Ultrasound in Obstetrics \& Gynecology, 16, 260-263. http://dx.doi.org/10.1046/j.1469-0705.2000.00212.x

[14] Kuojen, T., Vickie, A., Graig, T., Per, L., Hanmin, L., Michael, R., et al. (2002) Selective Reduction of Acardiac Twin by Radiofrequency Ablation. American Journal of Obstetrics and Gynecology, 187, 635-640. http://dx.doi.org/10.1067/mob.2002.125242

[15] Okai, T., Ichizuka, K., Hasegawa, J., Matsuoka, R., Nakamura, M., shimodaira, K., et al. (2013) First Successful Case of Non-Invaasive In-Utero Treatment of Twin Reversed Arterial Perfusion Sequence by High-Intensity Focused Ultrasound. Ultrasound in Obstetrics \& Gynecology, 42, 112-114. http://dx.doi.org/10.1002/uog.12466

[16] Marieke, H., Toon, T. and Yves, J. (2014) Late Presentation of Acardiac Twin: A Case Report and Review of Literature. OJOG, 4, 379-382. http://dx.doi.org/10.4236/ojog.2014.47056

[17] Hecher, K., Lewi, L., Gratacos, E., Huber, A., Villes, Y. and Deprest, J. (2006) Twin Reversed Arterial Perfusion: Fetoscopic Laser Coagulation of Placental Anastomoses or the Umbilical Cord. Ultrasound in Obstetrics \& Gynecology, 28, 688-691. http://dx.doi.org/10.1002/uog.3816

[18] Pagani, G., D’Antonio, F., Khalil, A., Papageorghiou, A. and Bhide, A. (2013) Intrafetal Laser Treatment for Twin Reversed Arterial Perfusion Sequence: Cohort Study and Meta-Analysis. Ultrasound in Obstetrics \& Gynecology, 42, 6-14. 
Scientific Research Publishing (SCIRP) is one of the largest Open Access journal publishers. It is currently publishing more than 200 open access, online, peer-reviewed journals covering a wide range of academic disciplines. SCIRP serves the worldwide academic communities and contributes to the progress and application of science with its publication.

Other selected journals from SCIRP are listed as below. Submit your manuscript to us via either submit@scirp.org or Online Submission Portal.
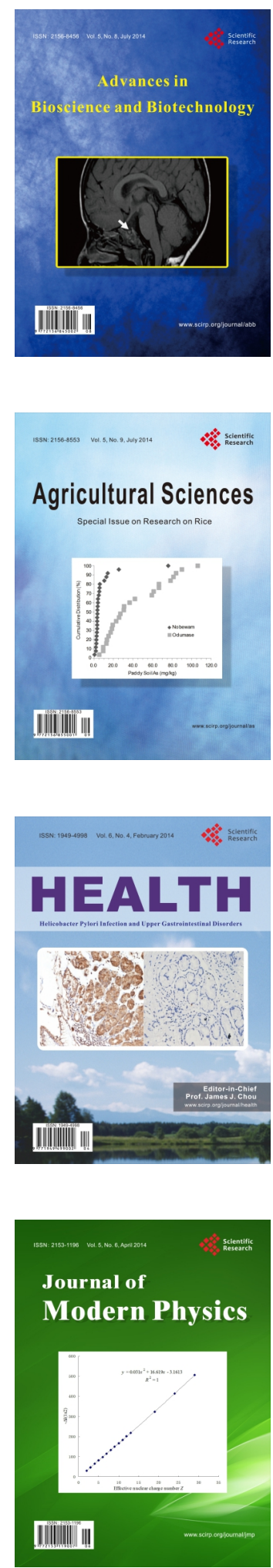
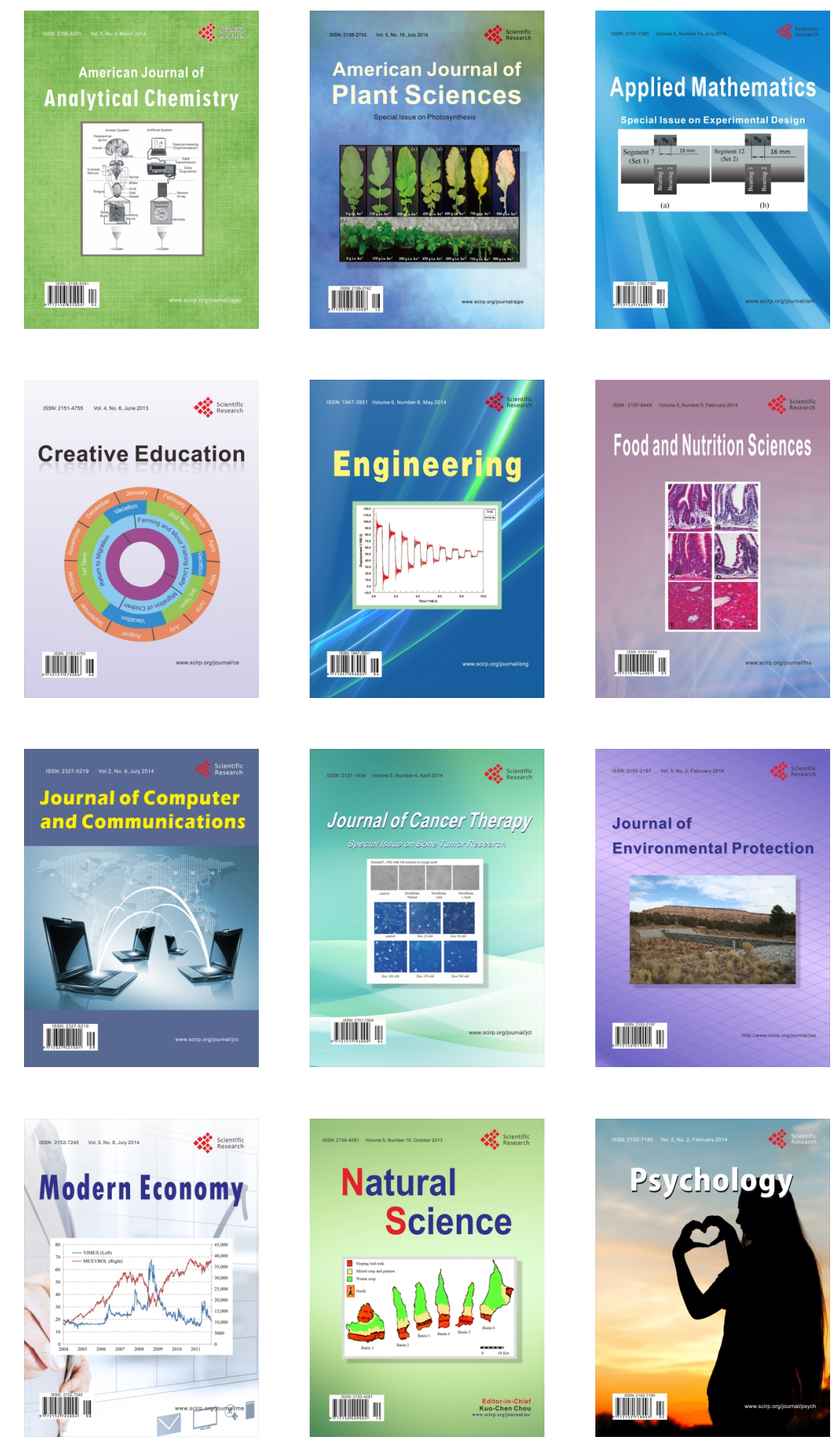